\title{
Effects of cognitive training based on metamemory and mental images
}

\author{
Thaís Bento Lima-Silva $a^{1}$ Tiago Nascimento Ordonez ${ }^{1}$, Glenda Dias dos Santos ${ }^{1}$, \\ Aline Teixeira Fabrício², Flávia Ogava Aramaki², Evany Bettine de Almeida², \\ Débora Lee Vianna-Paulo', Mayne Patrício Malagutti ${ }^{1}$, Ana Carolina Valente-Oliveira ${ }^{1}$, \\ Amanda Iwasaki², Gisele dos Santos Souza ${ }^{2}$, Mônica Sanches Yassuda ${ }^{3}$
}

\begin{abstract}
There is scant research evidence regarding training effects among elderly with limited educational experience. Research indicating an association between metamemory and memory performance is based on samples of older adults with at least 12 years of education. Objectives: To test the efficacy of a cognitive training program based on the creation of mental images and changes in specific aspects of metamemory in individuals with 3 to 15 years of education ( $M=8.38, S D=4.24)$. Methods: 37 older adults participated in five training sessions (Training Group (TG)) and 32 control subjects completed only pre and post test assessments (Control Group (CG)) including the Mini Mental Status Examination (MMSE), the Geriatric Depression Scale (GDS), the Brief Cognitive Screening Battery (BCSB) (naming and memorization of 10 pictures, animal category verbal fluency test, the Clock Drawing Test (CDT)), the Story subtest from the Rivermead Behavioural Memory Test (RBMT), the Memory Complaint Questionnaire (MAC-Q), and the Picture and Story domains from the Memory Self-Efficacy Questionnaire (MSEQ). Results: The TG showed significant improvement between pre and post tests on the delayed recall of the 10 pictures and in self-efficacy for the memorization of stories. These same changes were not found in the CG. Conclusions: Five-session cognitive training may lead to significant improvements in episodic memory and memory self-efficacy, an aspect of metamemory, in individuals with an average of 8 years of education. Key words: cognitive training, cognition, mental images, self-efficacy, metamemory, elderly, aging.
\end{abstract}

\begin{abstract}
Efeitos do treino cognitivo baseado em metamemória e imagens mentais
Resumo - Existem na literatura poucas evidências sobre os efeitos do treino cognitivo entre idosos com baixa escolaridade. Pesquisas que evidenciam a associação entre metamemória e o desempenho em tarefas de memória baseiam-se em amostras com idosos com 12 anos de escolaridade ou mais Objetivos: Testar a eficácia de um programa de treino cognitivo baseado na criação de imagens mentais e na alteração de aspectos da metamemória entre indivíduos entre 3 e 15 anos de escolaridade $(\mathrm{M}=8.38, \mathrm{SD}=4.24)$. Métodos: 37 adultos maduros e idosos participaram de cinco sessões de treino (Grupo Treino (GT)) e 32 somente completaram as avaliações pré e pósintervenção (Grupo Controle (GC)), com o Mini Exame do Estado Mental (MEEM), a Escala de Depressão Geriátrica (EDG), a Bateria Breve de Rastreio Cognitivo (BBRC) (nomeação e memorização de 10 figuras, fluência verbal animais, Teste do Desenho do Relógio), o subteste Estória do Teste Comportamental de Memória de Rivermead (RBMT), o Questionário de Queixas de Memória (MAC-Q), os domínios Figura e História do Questionário de Auto-Eficácia para Memória (MSEQ). Resultados: O GT apresentou ganho significativo entre o pré e o pós-teste no resgate tardio das 10 figuras e na auto-eficácia para a memorização de histórias. Estas alterações não foram encontradas no GC. Conclusões: O treino cognitivo de cinco sessões pode gerar melhora significativa em memória episódica e em auto-eficácia, um aspecto da metamemória, em indivíduos com 8 anos de escolaridade em média. Palavras-chave: treino cognitivo, cognição, imagens mentais, auto-eficácia, metamemória, idosos, envelhecimento.
\end{abstract}

\footnotetext{
${ }^{1}$ Bachelors in Gerontology, School of Arts, Sciences and Humanities, University of São Paulo, São Paulo SP, Brazil. ${ }^{2}$ Undergraduate Students in Gerontology, School of Arts, Sciences and Humanities, University of São Paulo, São Paulo SP, Brazil. ${ }^{3}$ Assistant Professor in Gerontology, School of Arts, Sciences and Humanities, University of São Paulo, São Paulo SP, Brazil.
}

Mônica Sanches Yassuda - Escola de Artes, Ciências e Humanidades / Universidade de São Paulo - Av. Arlindo Bettio 1000 / sala 345J - 03828-000 São Paulo SP - Brazil. E-mail: yassuda@usp.br

Disclosure: The authors report no conflicts of interest.

Received November 22, 2009. Accepted in final form April 22, 2010. 
Studies on cognitive plasticity have proven a fertile field for basic research since they yield essential information about human aging. Moreover, these studies have important implications for the clinical practice of gerontologists because optimizing memory is associated to health, autonomy and independence in the elderly. ${ }^{1}$

Studies investigating cognitive training differ not only in terms of duration, but specifically on the strategies taught and training methodologies employed. Thus, the results concerning the magnitude of effects, generalization for untrained tasks and long-term retention reported in the literature vary widely. ${ }^{2}$ Nevertheless, there is consensus that cognitive interventions can lead to significant performance improvements ${ }^{3}$ and recent data suggests that cognitive training can reduce age-associated functional decline. ${ }^{4}$

There is scant data from Brazilian studies regarding the efficacy of cognitive interventions in our elderly population, which tends to have lower levels of formal education. However, a recent study has reported significant gains in memory performance in older adults with four to eight years of schooling who underwent five training sessions involving categorization strategies. ${ }^{5}$ Participants who practiced using categorization with pictures and grocery lists outperformed control participants in similar tasks at post test. In another study involving illiterate and semi-literate older adults who received eight sessions of training based on categorization or mental images, results indicated that mental images might be more effective to improve memory performance among elderly with limited education. ${ }^{6}$

Memorization strategies based on the creation of interactive mental images have been described in previous successful studies on memory rehabilitation and training. ${ }^{7-9}$ These strategies stimulate the creation of a link between mental images and the information to be memorized. Although creating mental images may require cognitive resources such as concentration, they have been proven to be highly effective among older adults. ${ }^{7-9}$

Cognitive training studies also highlight that cognitive performance can be modulated by variables related to metamemory. ${ }^{10}$ The term metamemory originally referred to a broad array of knowledge held about the workings of memory. ${ }^{11}$ More recently, metamemory has been described as a latent construct which includes knowledge, perceptions and beliefs about one's own memory and about memory systems in general. ${ }^{12}$ In aging studies, a particular dimension of metamemory that has been regarded as relevant for daily living is memory self-efficacy. ${ }^{12,13}$ Memory selfefficacy refers to the level of confidence that an individual has in his/her own abilities to perform memory tasks ${ }^{10}$. In previous aging studies it has been related with motivation to perform memory tasks, degree of effort invested, use of strategies and perseverance on tasks. ${ }^{10-13} \mathrm{~A}$ recent study has also shown that memory self-efficacy at baseline could predict memory performance levels after six years. ${ }^{14}$

Cognitive interventions have targeted metamemory, including knowledge about memory and memory selfefficacy, as a means of enhancing the impact of training. ${ }^{15}$ Several training studies have attempted to educate older adults about memory and aging, alter negative beliefs about memory performance in later life, and improve memory self-efficacy, since metamemory has been associated with memory performance (for a review of this literature, refer to Dunlosky and Hertzog, ${ }^{9}$ in Brazil, refer to Yassuda et al. ${ }^{16}$ ).

There is limited research evidence regarding training effects among elderly with limited educational experience. Research indicating the association between metamemory and memory performance is based on samples of older adults with at least 12 years of education. Therefore, the aim of this study was to test the efficacy of a cognitive training program based on the creation of mental images and on the alteration of certain metamemory aspects, that is, perception of change and memory self-efficacy. This study sought to investigate whether an intervention containing these two elements could generate simultaneous or synergetic effects on cognitive performance and on metamemory measures. More specifically, the aim was to test whether this combined approach could generate significant effects among older adults with limited education.

\section{Methods \\ Participants}

A total of 69 older adults with 3 to 15 years of schooling $(\mathrm{M}=8.38, \mathrm{SD}=4.24)$ and enrolled in a university program for seniors took part in the study. Participants were randomly subdivided into a Training Group (TG) and a Control Group (CG). The TG comprised 37 subjects who received five training sessions, whereas the CG comprised 32 participants who did not participate in any training sessions. Subjects from both groups were submitted to pre and post-intervention assessments. Participants from the CG were later enrolled in a forthcoming intervention. There was no placebo condition to control for social interaction effects, and this is a limitation of the study.

\section{Materials}

All subjects underwent an initial assessment involving signing the Informed Consent form, completion of a sociodemographic questionnaire, and administration of the following instruments: Mini Mental State Exam (MMSE), ${ }^{17}$ Geriatric Depression Scale with 15 questions (GDS), ${ }^{18}$ the Brief Cognitive Screening Battery (BCSB) ${ }^{19}$ (naming and memorization of 10 pictures, animal category verbal flu- 
ency test, the Clock Drawing Test (CDT)), the Story subtest from the Rivermead Behavioural Memory Test (RBMT), ${ }^{20}$ the Memory Complaint Questionnaire (MAC-Q), ${ }^{21,22}$ and the Picture and Story domains from the Memory Self-Efficacy Questionnaire (MSEQ). ${ }^{16}$

MMSE scores range from 0 to 30 points and the following cut-off scores were adopted according to schooling level: for illiterates, 17 points; individuals with 1 to 4 years of schooling, 20 points; 5 to 8 years, 24 points; greater than 8 years of education, 26 points. These cut-off scores were adapted from Brucki et al. ${ }^{17}$ by calculating a standard deviation from the mean for each schooling level, and then rounding them down. In the present study, a cut-off score of 6 was adopted for the version of the GDS, with scores ranging from 0 to 15 points. The elderly individuals included in the sample presented scores which indicated absence of dementia (MMSE and BCSB) and no severe depression (GDS $>10)$. Only one older adult presented a score of 12 on the GDS during the pre-test. Data for this participant was maintained in study analyses because there was cognitive preservation in the MMSE and in the BCSB.

For the BCSB, performance was assessed based on the number of pictures named correctly $(0-10)$, the number of pictures correctly recalled in incidental memory (after naming, unaware of the memory task) (0-10), the number of pictures recalled after studying them for 30-seconds - immediate memory (0-10), and the number of pictures correctly recalled (0-10) after performing the verbal fluency task, and the Clock Drawing Test - delayed recall. We decided to omit the third chance to memorize the pictures (Learning) in order to reduce the risk of reaching ceiling effects at post-test. Verbal fluency consisted of counting the names of the animals mentioned, according to criteria by Brucki and Rocha. ${ }^{23}$ The CDT was corrected based on the criteria by Sunderland and colleagues, ${ }^{24}$ with scores between 0 and 10 .

The MAC-Q scale comprises six questions which aim to assess the perception of decline in memory tasks (in ten years for this study) involving five everyday situations, such as remembering telephone numbers or codes used on a daily or weekly basis, and a final question on overall mnemonic performance. Scores ranged from 0 to 35 points with higher scores being suggestive of greater concern about memory decline.

The MSEQ scale assesses the degree of confidence a person presents when performing certain memory tasks. The Picture and Story domains were selected because they were the tasks that matched most closely to the memory tasks contained in the protocol. At increasing levels of difficulty, individuals indicate if they would be able to complete a memorization task and if so, the degree of confidence with which they believe they could carry out the task. The scale produces two variables: the total number of times the person states they are able to perform the task ( 0 - 5 for each domain) and percentage means indicating the degree of confidence in the ability to carry out the tasks $(0-100 \%$ for each domain). Only percentage means were analyzed in this study.

\section{Procedures}

Each of the five training sessions included a 45-minute educational intervention aimed at offering information about memory and aging and at changing negative beliefs. This educational component followed a pre-determined protocol. In each session different memory sub-systems were explored, and aspects of memory which tend to remain stable with aging were highlighted. Special attention was given to the stability observed in immediate memory, semantic memory, and implicit memory. Everyday examples of tasks involving these sub-systems were used in order to avoid technical terms. In all sessions, participants were asked to report memory successes, i.e. occasions on which they managed to remember important information, with the objective of improving self-efficacy. After the educational intervention, participants were divided into small groups, led by Gerontology students, and spent $45 \mathrm{~min}$ utes learning to use mental images for memorizing words, phrases and short stories. Initially, they learned to use mental images to memorize single words, and short phrases. In the last two sessions they practiced using mental images to remember short stories. In all sessions, between the study phase and the recall phase, participants were challenged to perform fluency tasks, with categorical and phonemic restrictions. These tasks were carried out in a group format, and participants were enthusiastic about them. The students also followed a pre-determined protocol, and received training to reduce discrepancies among the groups.

\section{Statistical analyses}

Frequency tables for categorical variables (gender) provide the profile of the sample. Descriptive statistics (mean, standard deviation, minimum and maximum values) for the continuous variables were calculated, including scores for cognitive and self-efficacy scales. The chi-square test was employed in order to compare the categorical variable gender among groups. Student's $t$ test for independent samples was used to compare continuous variables between the two groups, when these were normally distributed. In order to assess changes from pre to post-test scores, deltas were calculated (post-test score subtracted from pre-test score) and the deltas for both groups were then compared using Student's $t$ test for independent samples. To confirm these results, repeated measures ANOVAs were also carried out, with Time as a within-subject factor (pre $\times$ post test) and 
Table 1. Means and standard deviation for sociodemographic data.

\begin{tabular}{lccc}
\hline & TG (37) & CG (32) & p-value \\
\hline Age & $65.32(6.11)$ & $63.66(5.78)$ & $0.251^{\mathrm{a}}$ \\
Schooling & $8.95(4.04)$ & $7.97(4.27)$ & $0.333^{\mathrm{a}}$ \\
Income & $2.92(1.74)$ & $2.41(1.24)$ & $0.169^{\mathrm{a}}$ \\
MMSE & $27.35(2.34)$ & $25.75(2.60)$ & $0.009^{\mathrm{a}}$ \\
GDS & $2.68(1.97)$ & $3.88(2.64)$ & $0.035^{\mathrm{a}}$ \\
No. of women & 34 & 22 & $0.032^{\mathrm{b}}$
\end{tabular}

${ }^{a} \mathrm{p}$-value refers to the Student $\mathrm{t}$ test for independent samples; ${ }^{\mathrm{b}} \mathrm{p}$-value refers to the chi-square test.

Group as between-subject factor (TG $\times$ CG), with Tukey post hoc testing. The level of significance adopted for the statistical tests was $5 \%(\mathrm{p}<0.05)$. Version 9.0 of the SPSS statistical package was used for all statistical analyses.

\section{Results}

Table 1 below presents the socio-demographic data for the total sample. With the exception of gender (there was a higher proportion of men in the CG), no significant difference was detected between the groups, i.e. the social demographic profiles of both groups were found to be similar for age, education and income. However, a significant difference was identified for MMSE and GDS - participants from the TG had higher performance on the MMSE and less depressive symptoms. The sample did not include illiterates, since all participants had at least three years of formal education.

The comparison of deltas of the TG and CG revealed a significant difference for MSEQ-Story and Delayed Memory on the BCSB. These data are shown in Table 2.

Repeated measures ANOVAS indicated a significant Time $\times$ Group interaction. Post hoc testing suggested that only the TG demonstrated performance increments from pre to post test, for MSEQ-Story and Delayed Memory on the BCSB. Results from ANOVAs and the delta analyses were congruent (Table 3 ).

\section{Discussion}

The aim of this study was to test the efficacy of a cognitive training program based on the creation of mental images and the alteration of meta-memory, particularly perception of cognitive chance and memory self-efficacy. The results suggest that the educational intervention concerning aspects of memory which tend not to change during aging, and highlighting of successful situations involving memory, can bring about positive change in memory self-efficacy. Furthermore, the results suggest that mental image-based training can lead to benefits in tasks demanding episodic memory.

The use of mental images in memory training studies in aging are now commonplace. Studies by Yesavage and
Table 2. Means and standard deviation (in parenthesis) for dependent variables for the TG $(n=37)$ and the CG $(n=32)$.

\begin{tabular}{|c|c|c|c|}
\hline Group & Pre-test $(n=69)$ & Post-test $(n=69)$ & Delta \\
\hline \multicolumn{4}{|c|}{ MSEQ Pictures } \\
\hline Training & $46.00(16.08)$ & $50.70(18.07)$ & $4.70(18.61)$ \\
\hline Control & $42.75(19.81)$ & $44.06(21.02)$ & $1.31(18.40)$ \\
\hline \multicolumn{4}{|c|}{ MSEQ Story } \\
\hline Training & $54.81(21.70)$ & $63.24(21.37)$ & $8.43(24.20)^{\mathrm{a}}$ \\
\hline Control & $59.62(37.07)$ & $50.70(23.81)$ & $-8.93(26.00)^{\mathrm{a}}$ \\
\hline \multicolumn{4}{|c|}{ MAC-Q } \\
\hline Training & $25.11(4.03)$ & $23.76(4.30)$ & $-1.35(5.36)$ \\
\hline Control & $24.66(6.13)$ & $25.13(0.20)$ & $0.46(3.29)$ \\
\hline \multicolumn{4}{|c|}{ BCSB Naming } \\
\hline Training & $9.97(0.16)$ & $10.00(0.00)$ & $0.03(0.16)$ \\
\hline Control & $9.97(0.18)$ & $9.97(0.18)$ & $0.00(0.25)$ \\
\hline \multicolumn{4}{|c|}{ BCSB Incidental Mem } \\
\hline Training & $6.16(1.19)$ & $7.54(1.22)$ & $1.38(1.60)$ \\
\hline Control & $6.19(1.60)$ & $7.09(1.28)$ & $0.90(1.78)$ \\
\hline \multicolumn{4}{|c|}{ BCSB Immediate Mem } \\
\hline Training & $8.65(1.18)$ & $9.14(1.06)$ & $0.49(1.04)$ \\
\hline Control & $8.50(1.44)$ & $8.72(1.25)$ & $0.22(1.16)$ \\
\hline \multicolumn{4}{|c|}{ BCSB Delayed Mem } \\
\hline Training & $7.78(1.46)$ & $9.03(0.96)$ & $1.25(1.46)^{\mathrm{a}}$ \\
\hline Control & $7.69(1.67)$ & $7.91(1.71)$ & $0.21(1.84)^{\mathrm{a}}$ \\
\hline \multicolumn{4}{|c|}{ Verbal Fluency } \\
\hline Training & $15.51(3.19)$ & $16.70(3.27)$ & $1.89(3.52)$ \\
\hline Control & $14.00(4.50)$ & $14.63(4.43)$ & $0.62(3.50)$ \\
\hline \multicolumn{4}{|c|}{ Clock Drawing Test } \\
\hline Training & $8.32(1.40)$ & $8.49(1.41)$ & $0.16(1.59)$ \\
\hline Control & $6.41(3.15)$ & $7.22(2.49)$ & $0.81(0.72)$ \\
\hline \multicolumn{4}{|c|}{ Story RBMT } \\
\hline Training & $6.54(1.54)$ & $7.14(2.71)$ & $0.60(2.82)$ \\
\hline Control & $5.25(2.18)$ & $5.22(2.04)$ & $-0.03(2.25)$ \\
\hline \multicolumn{4}{|c|}{ Delayed Recall Story RBMT } \\
\hline Training & $5.86(1.84)$ & $6.78(2.50)$ & $0.92(2.70)$ \\
\hline Control & $4.78(2.22)$ & $4.81(2.38)$ & $0.04(2.96)$ \\
\hline \multicolumn{4}{|c|}{ GDS } \\
\hline Training & $2.68(1.97)$ & $2.57(1.86)$ & $-0.19(1.62)$ \\
\hline Control & $3.88(2.64)$ & $3.31(2.31)$ & $-0.56(1.31)$ \\
\hline
\end{tabular}

andicates statistically significant difference between groups for deltas on Student's $\mathrm{t}$ test for independent samples, $\mathrm{p}<0.05$.

colleagues $^{8}$ conducted in the 1980 s demonstrated the efficacy of mental images for memorizing face and name pairs. However, compared to the use of verbal mediators, mental images are relatively less studied as memory aids..$^{25}$ There is very limited information on their efficacy when used by older adults with less than 12 years of education.

In a training study based on the creation of mental images and categorization, Salmazo and Yassuda ${ }^{6}$ demonstrated that the use of mental images can be effective for 
Table 3. Results for the ANOVAS comparing scores for the TG and the CG at pre and post test.

\begin{tabular}{lccc}
\hline Variables & $\begin{array}{c}\text { Group } \\
(\mathrm{TG} \times \mathbf{C G})\end{array}$ & $\begin{array}{c}\text { Time } \\
(\text { Pre } \times \text { Post Test })\end{array}$ & $\begin{array}{c}\text { Interaction effects } \\
(\text { Group } \times \text { Time })\end{array}$ \\
\hline MSEQ Pictures & $\mathrm{F}_{(1,67)}=1.59 ; \mathrm{p}=0.212$ & $\mathrm{~F}_{(1,67)}=1.81 ; \mathrm{p}=0.183$ & $\mathrm{~F}_{(1,67)}=0.58 ; \mathrm{p}=0.451$ \\
MSEQ Story & $\mathrm{F}_{(1,67)}=0.56 ; \mathrm{p}=0.458$ & $\mathrm{~F}_{(1,67)}=0.01 ; \mathrm{p}=0.934$ & $\mathrm{~F}_{(1,67)}=8.25 ; \mathrm{p}=0.005^{\mathrm{a}}$ \\
MAC-Q & $\mathrm{F}_{(1,67)}=0.17 ; \mathrm{p}=0.686$ & $\mathrm{~F}_{(1,67)}=0.65 ; \mathrm{p}=0.422$ & $\mathrm{~F}_{(1,67)}=2.78 ; \mathrm{p}=0.100$ \\
BCSB Naming & $\mathrm{F}_{(1,67)}=0.51 ; \mathrm{p}=0.478$ & $\mathrm{~F}_{(1,67)}=0.28 ; \mathrm{p}=0.597$ & $\mathrm{~F}_{(1,67)}=0.28 ; \mathrm{p}=0.597$ \\
BCSB Incidental Mem & $\mathrm{F}_{(1,67)}=0.74 ; \mathrm{p}=0.393$ & $\mathrm{~F}_{(1,67)}=31.35 ; \mathrm{p}=<0.001^{\mathrm{b}}$ & $\mathrm{F}_{(1,67)}=1.34 ; \mathrm{p}=0.251$ \\
BCSB Immediate Mem & $\mathrm{F}_{(1,67)}=1.13 ; \mathrm{p}=0.292$ & $\mathrm{~F}_{(1,67)}=7.08 ; \mathrm{p}=0.010^{\mathrm{c}}$ & $\mathrm{F}_{(1,67)}=1.02 ; \mathrm{p}=0.316$ \\
BCSB Delayed Mem & $\mathrm{F}_{(1,67)}=4.35 ; \mathrm{p}=0.041^{\mathrm{d}}$ & $\mathrm{F}_{(1,67)}=13.48 ; \mathrm{p}=<0.001^{\mathrm{d}}$ & $\mathrm{F}_{(1,67)}=6.62 ; \mathrm{p}=0.012^{\mathrm{d}}$ \\
Verbal Fluency & $\mathrm{F}_{(1,67)}=4.71 ; \mathrm{p}=0.034^{\mathrm{e}}$ & $\mathrm{F}_{(1,67)}=4.59 ; \mathrm{p}=0.036^{\mathrm{e}}$ & $\mathrm{F}_{(1,67)}=0.44 ; \mathrm{p}=0.508$ \\
Clock Drawing Test & $\mathrm{F}_{(1,67)}=12.14 ; \mathrm{p}=0.001^{\mathrm{f}}$ & $\mathrm{F}_{(1,67)}=3.41 ; \mathrm{p}=0.069$ & $\mathrm{~F}_{(1,67)}=1.52 ; \mathrm{p}=0.222$ \\
Story RBMT & $\mathrm{F}_{(1,67)}=14.60 ; \mathrm{p}=<0.001^{\mathrm{g}}$ & $\mathrm{F}_{(1,67)}=0.82 ; \mathrm{p}=0.368$ & $\mathrm{~F}_{(1,67)}=1.01 ; \mathrm{p}=0.317$ \\
Delayed Recall Story RBMT & $\mathrm{F}_{(1,67)}=13.15 ; \mathrm{p}=0.001^{\mathrm{h}}$ & $\mathrm{F}_{(1,67)}=1.94 ; \mathrm{p}=0.168$ & $\mathrm{~F}_{(1,67)}=1.70 ; \mathrm{p}=0.197$ \\
GDS & $\mathrm{F}_{(1,67)}=3.81 ; \mathrm{p}=0.055$ & $\mathrm{~F}_{(1,67)}=3.46 ; \mathrm{p}=0.067$ & $\mathrm{~F}_{(1,67)}=1.59 ; \mathrm{p}=0.212$ \\
MMSE & $\mathrm{F}_{(1,67)}=9.34 ; \mathrm{p}=0.003^{\mathrm{i}}$ & $\mathrm{F}_{(1,67)}=5.54 ; \mathrm{p}=0.022^{\mathrm{i}}$ & $\mathrm{F}_{(1,67)}=0.02 ; \mathrm{p}=0.903$ \\
\hline
\end{tabular}

Note: $\mathrm{F}_{(\mathrm{a}, \mathrm{b})}=\mathrm{F}$ statistics with "a" as degrees of freedom in the numerator and " $\mathrm{b}$ " as degrees of freedom in the denominador. N=61. ${ }^{a}$ Significant interaction, Tukey test TG: Pre $<$ Post ( $p=0.041$ ); CG: Pre=Post ( $\mathrm{p}=0.061)$; ${ }^{\mathrm{b}}$ Significant differences for both groups: Pre $<$ Post (TG: $p<0.001$ and CG: $\left.p=0.007\right)$; ${ }^{\mathrm{c}}$ TG: Pre $<$ Post ( $\left.\mathrm{p}=0.007\right)$; CG: Pre=Post

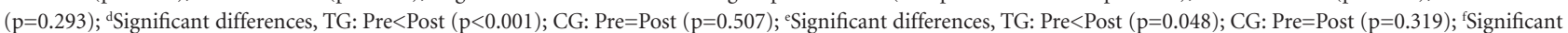
differences, TG $>C G$, at pre ( $p>0.001)$ and post ( $\mathrm{p}=0.010)$; ${ }^{\mathrm{g}}$ Significant differences, TG $>$ CG, pre $(\mathrm{p}>0.006)$ and post $(\mathrm{p}=0.002)$; ${ }^{\mathrm{h}}$ Significant differences, TG: Post $>$ Pre ( $\left.\mathrm{p}=0.046\right)$; CG: Pre=Post ( $\mathrm{p}=0.953)$; iSignificant differences, TG: Post=Pre $(\mathrm{p}=0.146)$; CG: Pre=Post $(\mathrm{p}=0.060)$.

improving performance on episodic memory tasks among elderly who are illiterate or have very low education. Therefore, the present study contributes to the current training literature, suggesting that mental images may also lead to performance changes among elders with an average of 8 years of education.

The method of creating mental images employed in the present study differed from methods used in previous studies. Yesavage ${ }^{26}$ used images by famous painters and highlighted the differences and similarities between the works of art. In the study by Brooks III et al., ${ }^{27}$ creating mental images was a stage preceding the teaching of two types of strategies, namely, face-name associations and the method of loci. The elderly were asked to analyze the images and associate short verbal sentences intended to facilitate name recall in the face-name strategy or the order of items in the method of loci strategy. The results revealed that, although the visualization pre-training was given prior to the strategies training for both groups, the group which trained using the method of loci showed greater improvement in the post-test than the group which practiced with the facename strategy. In the cited study, after teaching both memorization strategies, a memory questionnaire was applied before and after the interventions. The authors found that participants had a greater knowledge on strategies after the training. By contrast, in the present study, knowledge about memory was not assessed and this represents a study limitation since participants might have shown changes in this important aspect of metamemory due to the educational component of the intervention.

Previous studies have indicated that training programs which incorporate principles of self-efficacy theory have a significant potential to improve older adults' cognitive abilities. ${ }^{15}$ In the present study, some aspects of the intervention were in line with self-efficacy theory, such as the fact that aspects of memory which do not change significantly in later life were discussed in every session, and that successful memory experiences were constantly brought to the attention of the class. In addition, memory exercises were organized in such a way that easier tasks always preceded difficult ones, enhancing older adults' confidence in their memory abilities. Current findings support the results from West and colleagues, ${ }^{15}$ as they also suggest that integrated training programs which target mnemonic techniques as well as aspects of metamemory may be beneficial for seniors who frequently worry about their memory performance.

In the present study, older adults in the TG were encouraged to create mental models in episodic memory exercises. Subjects were exposed to words, short phrases and stories, and were encouraged to highlight the differences and similarities between the imagery created by each participant. Participants may have used the creation of mental images in the post-test and this in turn could explain the enhanced performance in the delayed recall of pictures. However, the use of strategies was not objectively assessed in the present study and constitutes another study limita- 
tion. Future training studies should include strategy use measures. Other limitations include the relatively low number of training sessions, since more sessions might have led to greater improvements. Further training studies should be conducted involving a higher number of sessions and longitudinal follow up assessments to check if training gains persist over time. Nonetheless, this study can contribute to the gerontological literature in that it involved community dwelling older adults, used scales previously adapted for the Brazilian elderly population, and included a control group. Preserved cognitive function can improve the quality of life among the elderly because it allows them to remain active and independent longer. ${ }^{4}$ Therefore, further studies are warranted on this increasingly important topic.

\section{References}

1. Ramos LR. Fatores determinantes do envelhecimento saudável em idosos residentes em centro urbano: Projeto Epidoso, São Paulo. Cad Saúde Pública 2003;19:793-797.

2. Loewenstein AD, Amigo E, Duara R, et al. A new scale for the assessment of functional status in Alzheimer Disease and related disorders. J Gerontol 1989;4:114-121.

3. Verhaeghen P, Marcoen A, Goosens L. Improving memory performance in the aged through mnemonic training: a metaanalytic study. Psychol Aging 1992;7:242-251.

4. Willis SL, Tennstedt SL, Marsiske M, et al. For the ACTIVE Study Group, Long-term effects of cognitive training on everyday functional outcomes in older adults. JAMA 2006;296: 2805-2814.

5. Carvalho FCR. Treino de memória episódica com idosos normais. Dissertação (Mestrado em Gerontologia) disponível na biblioteca digital da Unicamp - Faculdade de Educação, Universidade Estadual de Campinas, São Paulo, 2006.

6. Salmazo-Silva H, Yassuda MS. Memory training for older adults with low education: mental images versus categorization. Educ Gerontol 2009;35:890-905.

7. West LR. Compensatory strategies for age-associated memory impairment. In: Baddeley AD, Wilson BA, Watts FN. Editors. Handbook of memory disorders. John Wiley \& Sons; 1995;20:481-500.

8. Yesavage JA. Imagery pretraining and memory training in the elderly. Gerontology 1983;29:271-275.

9. Dunlosky J, Hertzog, C. Training programs to improve learning in later adulthood: Helping older adults educate themselves. In: Hacker DJ, Dunlosky J, Graesser AC, Editors. Metacognition in educational theory and practice. New Jersey London, Mahwah, NJ: Erlbaum;1998:249-276.

10. West RL, Yassuda MS. Aging and memory control beliefs: performance in relation to goal setting and memory self-evaluation. J Gerontol B Psychol Sci Soc Sci 2004;59:P56-P65.

11. Flavell JH, Wellman HM. Metamemory. In: Kail RV, Hagen JW, Editors. Perspectives on the development of memory and cognition. Hillsdale, NL: Erlbaum;1977:3-34.
12. Berry JM. Memory self-efficacy in its social cognitive context. In: Hess TM, Blanchard-Fields F, Editores. Social cognition and aging. San Diego: Academic Press; 1999:69-96.

13. Lovelace EA. Aging and metacognitions concerning memory function. In: Lovelace EA, Editor. Aging and cognition: mental processes, self awareness, and interventions, Amsterdam: Elsevier; 1990:157-188.

14. Valentijn SAM, Hill RD, Van Hooren SAH, et al. Memory selfefficacy predicts memory performance: results from a 6-year follow-up study. Psychol Aging 2006;21:165-172.

15. West RL, Bagwell DK, Dark-Freudeman A. Self-efficacy and memory aging: the impact of a memory intervention based on self-efficacy. Aging Neuropsychol Cogn 2008;15:302-329.

16. Yassuda MS, Batistoni SST, Fortes AG, Neri AL. Treino de memória no idoso saudável: benefícios e mecanismos. Psicol Refl Crít 2006;19:470-481.

17. Brucki SMD, Nitrini R, Caramelli P, Bertolucci PHF, Okamoto IH. Sugestões para o uso do Mini-Exame do Estado Mental. Arq Neuropsiquiat 2003;61:777-781.

18. Almeida OP. Queixas de problemas com a memória e o diagnóstico de demência. Arq Neuropsiquiatria 1998;56:412-418.

19. Vitiello APP, Ciriaco JGM, Takahashi DY, Nitrini R, Caramelli P. Avaliação cognitiva breve de pacientes atendidos em ambulatórios de neurologia geral. Arq Neuropsiquiatr 2007;65:299-303.

20. Yassuda MS, Flaks MK, Viola LF, et al. The psychometric characteristics of the Rivermead Behavioral Memory Test (RBMT) an early detection instrument for dementia and mild cognitive impairment in Brazil. International Psychogeriatrics (in press).

21. Crook TH, Feher, EP, Larabee GJ. Assessment of memory complaint in age-associated memory impairment: the MAC-Q. Int Psychogeriatr 1992;2:165-175.

22. Mattos P, Lino V, Rizo L, Alfano A, Araújo C, Raggio R. Memory complaints and test performance in healthy elderly persons. Arq Neuropsiquiatr 2003;61:920-924.

23. Brucki SMD, Rocha MSG. Category fluency test: effects of age, gender and education on total scores, clustering, in Brazilian Portuguese-speaking subjects. Braz J Med Biol Res 2004; 37:1771-1777.

24. Sunderland T, Hill JL, Mellow AM, et al. Clock drawing in Alzheimer's disease: A aovel measure of dementia severity. J Am Geriatr Soc 1989;37:725-729.

25. West LR. Compensatory strategies for age-associated memory impairment. In: Baddeley AD, Wilson BA, Watts FN, Editors. Handbook of memory disorders. New York: John Wiley e Sons Ltda; 1995:481-500.

26. Yesavage JA. Relaxation and memory training in 39 elderly patients. Am J Psychiatry 1984;141:778-781.

27. Brooks III JO, Friedman L, Pearman AM, Gray C, Yesavage JA. Mnemonic training in older adults: effects of age, length of training and type of cognitive training. Int Psychogeriatr 1999;11:75-84. 